\title{
Impact of Selected Technical Soil Parameters on the Greenhouse Energy Management
}

\author{
Grzegorz Nawalany ${ }^{1 *}$, Paweł Sokołowski ${ }^{1}$ \\ 1 University of Agriculture in Krakow, Faculty of Environmental Engineering, Department of Rural Building, \\ Al. Mickiewicza 24/28, 30-059 Kraków, Poland \\ * Corresponding author's e-mail: grzegorz.nawalany@urk.edu.pl
}

\begin{abstract}
The paper is an attempt to determine the impact of soil type and its selected technical parameters on the heat exchange with soil. The test results were based on the all-year-round experimental measurements of soil temperature and indoor and outdoor air in a greenhouse located in southern Poland. The field tests results were used to validate the calculation model using the WUFIplus software. The validation showed a high degree of conformity between the experiments and calculations. Five variants were used in the calculations, differentiated by technical parameters of the soil underneath the greenhouse. The results showed a significant impact of the soil type on the greenhouse energy management.
\end{abstract}

Keywords: heat exchange with soil, greenhouse, energy management, soil type

\section{INTRODUCTION}

Greenhouses have a significant share in production of vegetables and fruit and flowers. The main reason is ability to maintain the optimum temperature and air humidity as well as the appropriate level of insolation (Hassanien R. et al., 2018 and 2016; Sethi and Sharma, 2007). Modern, continuously developing automation allows reducing the labour and increasing the productivity (Liang M.H. et al., 2018; Taki et al., 2018; Wang et al., 2018; Canadas et al., 2017; Sagrado et al., 2016). A large and good-quality crop is possible only when the plants have the optimum growing conditions. Modern greenhouses should meet these requirements, hence their design and equipment is continuously being improved (Esen and Yuksel, 2013; Vadiee and Martin, 2013; Kurpaska, 2008; Papadopoulos and Hao, 1997). However, there are still some potential in terms of microclimate improvement in the growing zone, among other things obtaining the appropriate heat exchange with soil (Fox et al., 2019; Boughanmi et al., 2018; Nawalany et al., 2017, 2014; Kurpaska et al., 2012).
In order to ensure the appropriate temperature in a greenhouse in the areas with transitional climate, it is necessary to heat the greenhouse in the winter. The heating of a greenhouse whose envelope is made of glass involves large heat losses to the atmosphere, and the larger the temperature difference between the indoor air temperature and the outdoor temperature, the larger the losses (Bibbiani et al., 2016; Raczek and Wachowicz, 2014). In order to limit the energy losses in greenhouses, the transparent envelope is nowadays most often made of polycarbonate panels with solar radiation transmission coefficient similar to that of glass. The studies (Fabrizio, 2012) showed that the use of transparent plastics, which have better thermal properties than glass and do not disturb the solar radiation transmission significantly, can reduce the greenhouse energy demand even by $30 \%$.

In the energy balance of buildings, depending on their function, some role is played by the soil (Nawalany and Sokołowski, 2019; Nawalany et al., 2017b; Nawalany and Sokołowski, 2016). The role of soil in the greenhouse is very important, as it can significantly improve the thermal 
conditions in the growing zone and contribute to the reduced greenhouse energy demand (Nawalany et al., 2017a).

The studies conducted in greenhouses were mainly limited to the periods when the outdoor temperature is above freezing (Tong et. al., 2009; Kittas et. al., 2005), and the soil temperature under the greenhouse was studied only in the surface layer (Al-Kayssi, 2002). However, it is the winter when the role of soil in developing the thermal conditions inside the greenhouse increases. The soil heated up in the summer gives up the heat to the inside of the greenhouse which positively affects the limitation of sudden air temperature fluctuations in the growing zone (Nawalany et al., 2014, 2017a).

The knowledge of temperature distribution in the soil underneath the greenhouse is a basis to conduct further studies on determination of the soil impact on the greenhouse energy management. This paper deals with the impact of selected technical soil parameters such as density, specific heat and thermal conductivity coefficient on the greenhouse energy management. The results of the studies will allow a further improvement of material and design solutions of greenhouses which will reduce the heating energy demand in such facilities.

\section{MATERIALS AND METHODS}

The experimental studies of temperature distribution in soil were conducted in a typical detached greenhouse in a horticultural farm located in Małopolskie Province in southern Poland. The greenhouse was a steel frame, single-bay design, resting on a concrete continuous footing $1.0 \mathrm{~m}$ below the ground level. Neither the foundation nor the greenhouse floor were thermally insulated. The walls and roof were single $4 \mathrm{~mm}$-thick glazed units. The greenhouse was used to grow flowers (carnations). There were $0.35 \mathrm{~m}$-wide concrete pathways between the rows of grown flowers. The greenhouse ventilation was by gravity. The air exchange was effected by mechanically lifted ventilators in the top part of the walls and the roof. The heating was central, with tube radiators placed along the side walls, $2.5 \mathrm{~m}$ above the floor.

The study of soil under and in the surrounding of the greenhouse has shown a $1.5 \mathrm{~m}$-thick sandy clay layer $0.1 \mathrm{~m}$ under the humus layer.

The measuring section I-I with 3 measuring lines was located in the middle of the greenhouse (Fig. 1).

The soil temperature $\left(\Theta_{\mathrm{G}}\right)$ was measured using twelve PT-100 sensors with $\pm 0.1^{\circ} \mathrm{C}$ accuracy. The indoor air temperature was measured with

a)

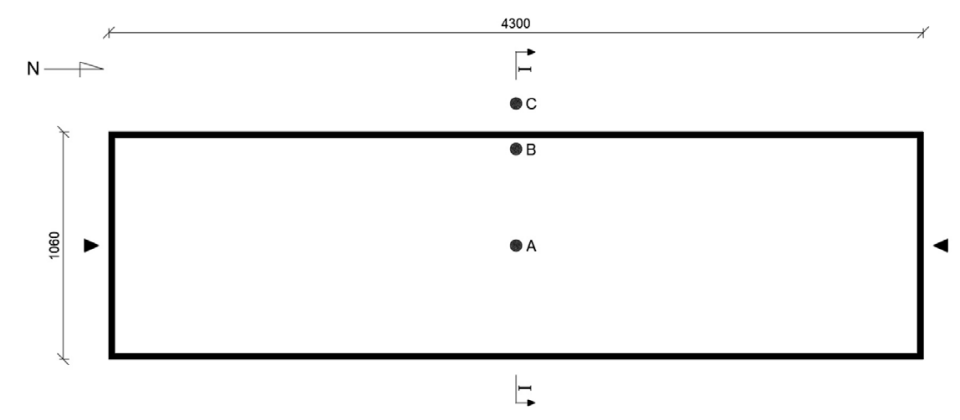

b)

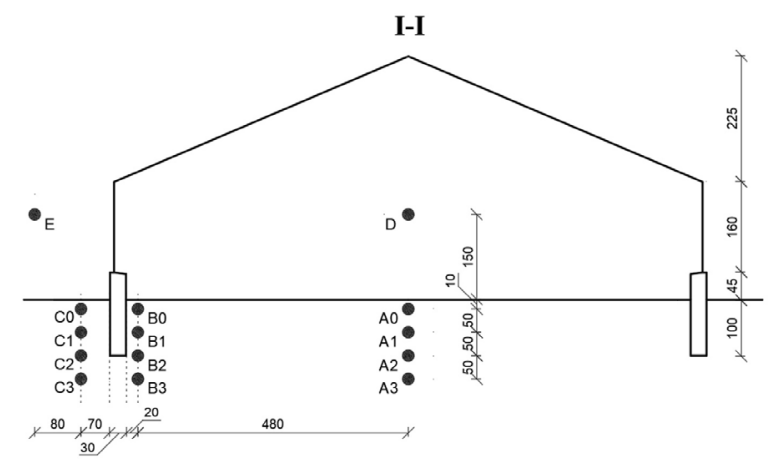

Fig. 1. Soil temperature measuring points under the greenhouse and in its surrounding: $a-$ plan, $b-$ section. 
a PT-100 sensor placed at the height of $1.50 \mathrm{~m}$. The outdoor air temperature was measured with a PT-100 sensor placed in a Stevenson screen. The frequency of soil and air temperature measurement was 1 hour, and the results were recorded by a multichannel Data Logger from HP.

The calculations of heat flow in soil were made using the WUFIplus software. The results of indoor and outdoor air temperature measurements were used to determine the boundary conditions, and the measured temperatures in soil to compare with the results of theoretical calculations. The calculation model assumes a separation of a rectangular prism of soil under the building and in its surrounding in which a three-dimensional heat flow occurs. Figure 2 presents a separated soil area with division into differential elements, along with the surfaces of action of indoor

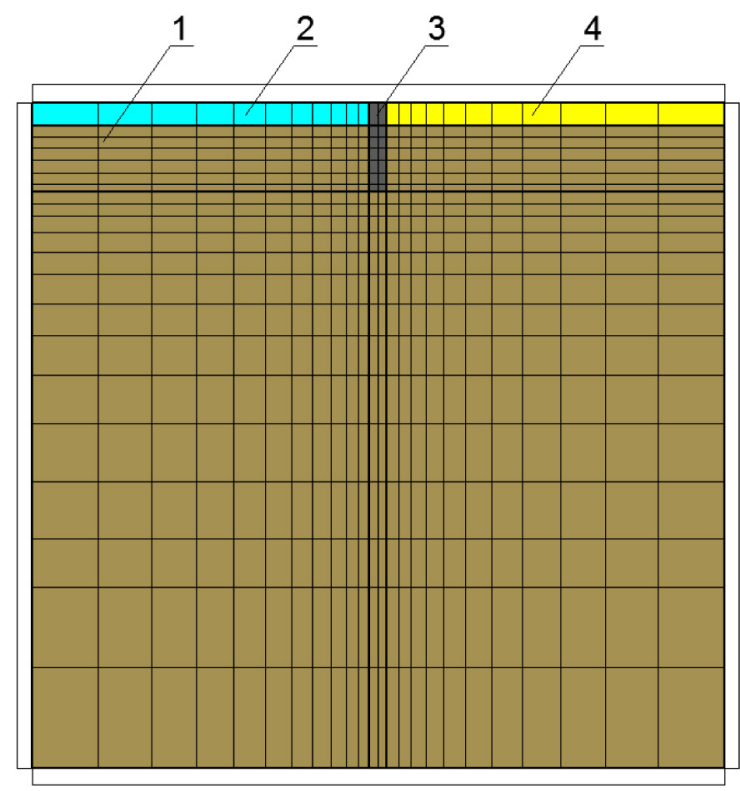

Fig. 2. Spatial division into differential elements (floor at ground level, uninsulated foundation): 1 - soil, 2 - outdoor air, 3 - concrete foundation, 4 - indoor air microclimate and outdoor climate and the soil area under the greenhouse and in its surrounding that was used in theoretical calculations.

The calculations of heat exchange with soil were made for 5 variants accounting for various soil types under the greenhouse:

- variant I - as-is state (validation), sandy clay;

- variant II - medium sand;

- variant III - gravel;

- variant IV - volcanic tuff;

- variant $\mathrm{V}$ - sandstone.

The technical parameters of the floor, transparent envelopes, foundation walls and soil are presented in Table 1.

The validation of the calculation model was based on the results of all-year-round experimental studies of temperature distribution in the soil under the greenhouse. It was assumed that the most important factors affecting the heat flow between the greenhouse and the soil are the indoor air temperature $\left(\Theta_{i}\right)$ and the outdoor air temperature $\left(\Theta_{e}\right)$. Deru and co-authors (2003) also used the same assumption during their studies on heat losses to soil in residential buildings.

\section{RESULTS AND DISCUSSION}

The selected soil temperature curves for field measurements and calculation variants are presented in Figure 3. The calculated soil temperature curves showed a good similarity to the results of long-term measurements conducted in the greenhouse, in actual conditions. The statistical compatibility of measured and calculated data is shown as box plots in Figure 4.

The obtained calculation results indicate a variation of soil contribution to the heat exchange depending on the soil types under the greenhouse. The heat flow direction in the soil

Table 1. Technical parameters of materials used in the calculation model

\begin{tabular}{|l|c|c|c|c|c|c|c|}
\hline \multicolumn{1}{|c|}{ Physical parameter } & $\begin{array}{c}\text { Concrete } \\
\text { w/c } 0,4\end{array}$ & $\begin{array}{c}\text { Single } \\
\text { glazed units }\end{array}$ & Sandy clay & $\begin{array}{c}\text { Medium } \\
\text { sand }\end{array}$ & Gravel & Volcanic tuff & Sandstone \\
\hline Density $\left[\mathrm{kg} \cdot \mathrm{m}^{-3}\right]$ & 2322 & - & 1800 & 1650 & 1800 & 1600 & 2500 \\
\hline Specific heat $\left[\mathrm{J}^{\left.-\mathrm{kg}^{-1} \cdot \mathrm{K}^{-1}\right]}\right.$ & 850 & - & 840 & 840 & 840 & 1000 & 920 \\
\hline $\begin{array}{l}\text { Thermal conductivity } \\
\text { coefficient }\left[\mathrm{W} \cdot \mathrm{m}^{-1} \cdot \mathrm{K}^{-1}\right]\end{array}$ & 1.70 & - & 0,70 & 0,40 & 0,90 & 0,55 & 2,30 \\
\hline $\begin{array}{l}\text { Average coefficient of } \\
\text { insolation heat gains }[-]\end{array}$ & - & 0.85 & - & - & - & - & - \\
\hline $\begin{array}{l}\text { Heat transfer coefficient } \\
{\left[\mathrm{W} \cdot \mathrm{m}^{-2} \cdot \mathrm{K}^{-1}\right]}\end{array}$ & - & 5.00 & - & - & - & - & - \\
\hline
\end{tabular}

Source: based on PN-EN ISO 6946:2008 
and the heat exchange intensity depend, inter alia, on thermal conditions in individual months of the study (Fig. 5). The analysis of results has shown that the highest monthly heat gains from

a)

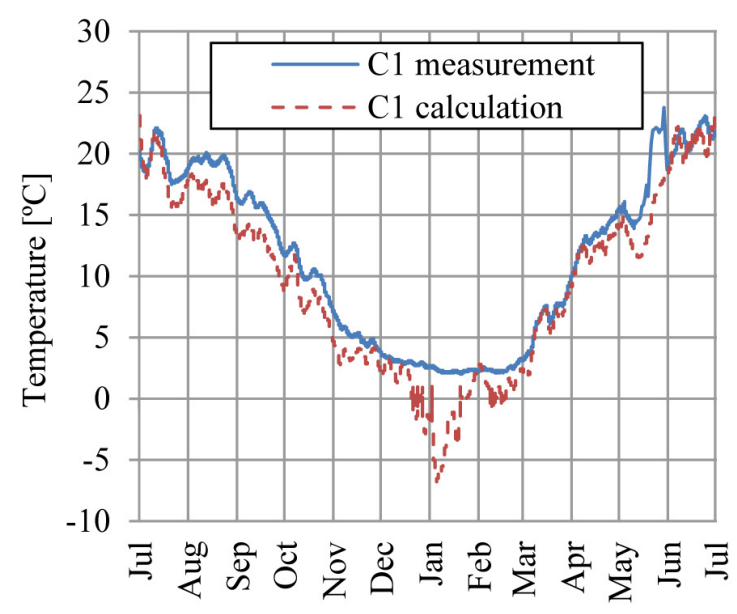

c)

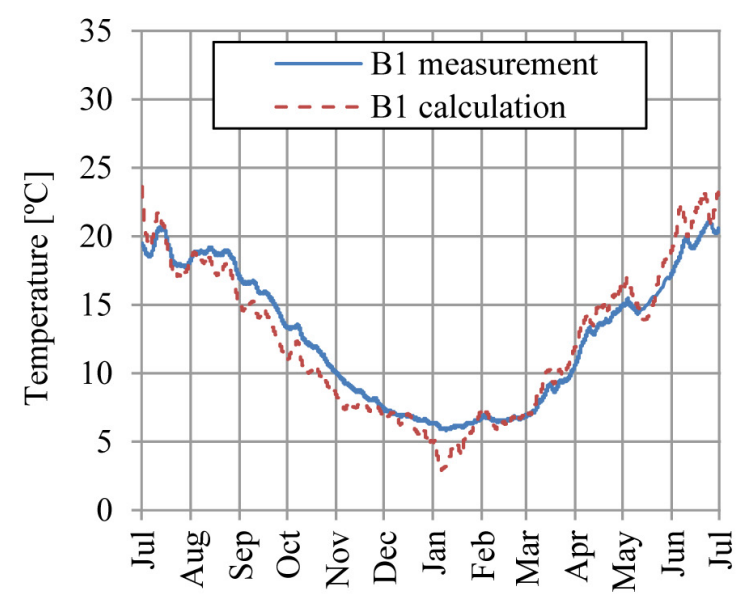

e)

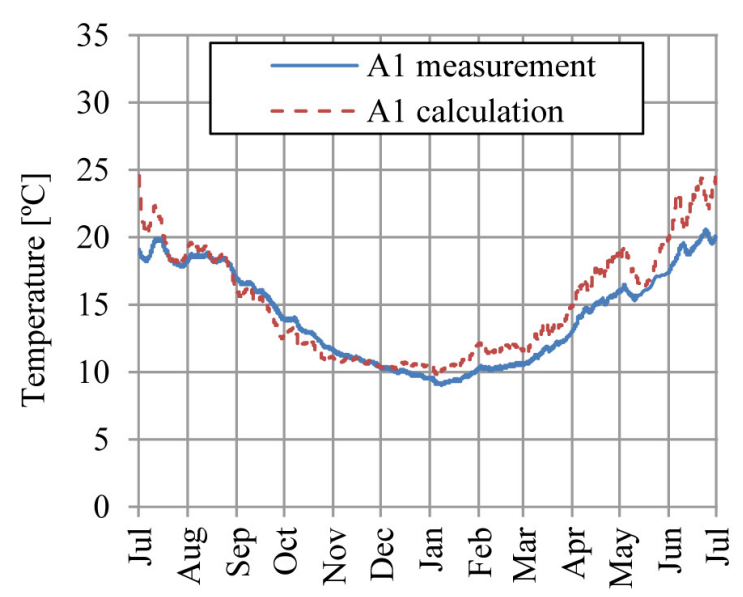

soil were obtained for variant $\mathrm{V}$ (sandstone) in October $(59.70 \mathrm{kWh})$. The lowest heat gains were obtained for variant II (medium sand) in October $(53.54 \mathrm{kWh})$. The highest heat losses to soil

b)

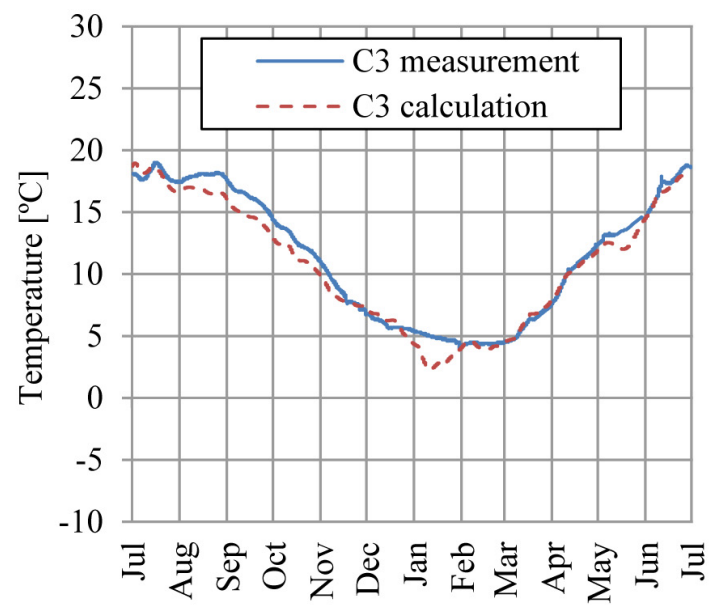

d)

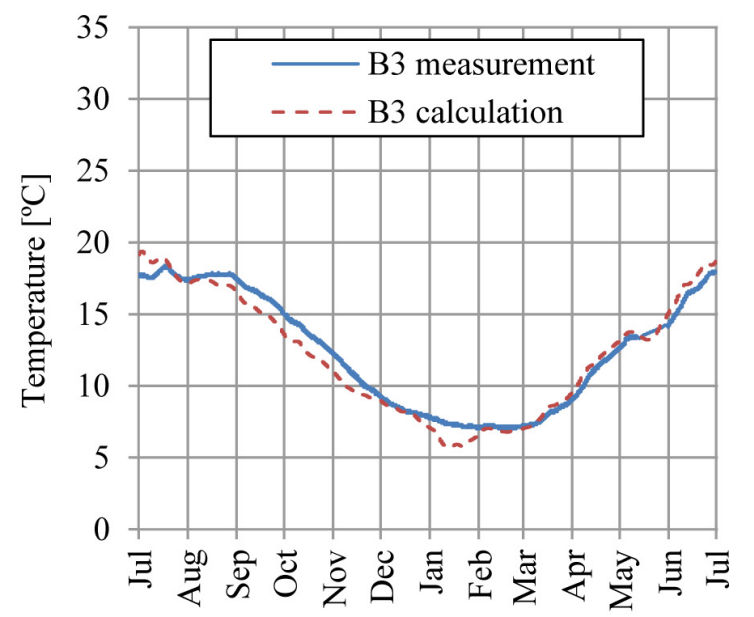

f)

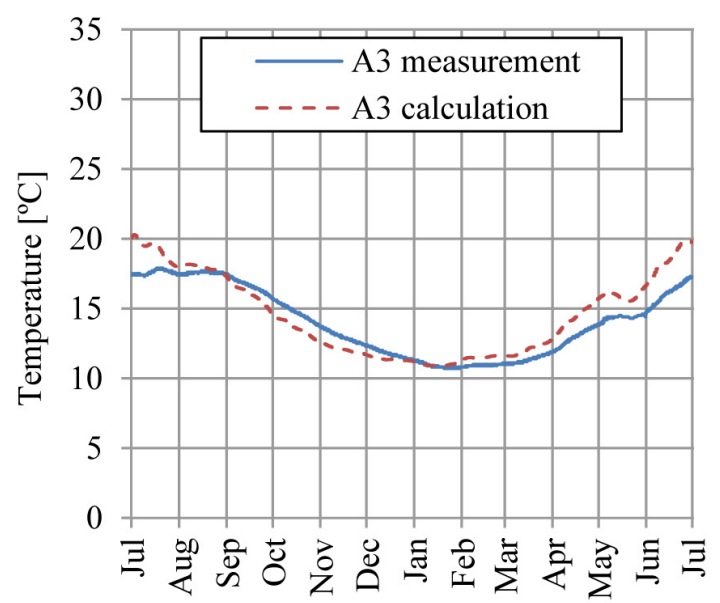

Fig. 3. Measured and calculated temperature in selected points: $a-C 1, b-C 3, c-B 1, d-B 3, e-A 1, f-A 3$. 


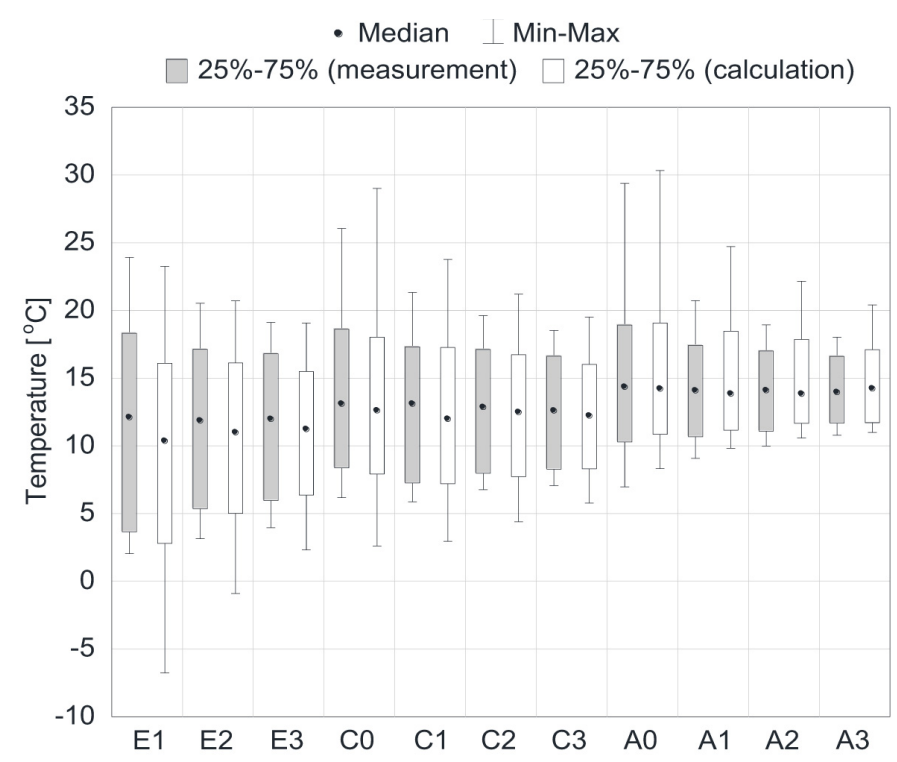

Fig. 4. Statistical comparison of measured and calculated data
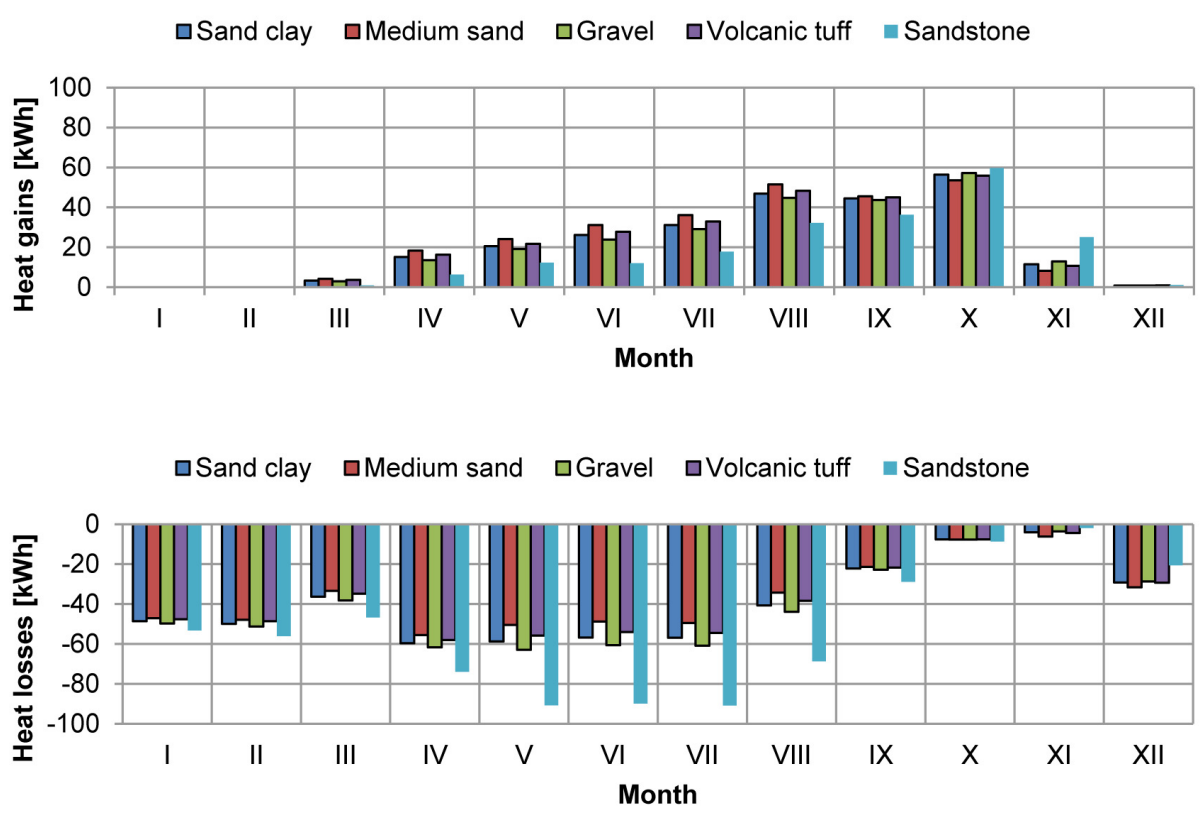

Fig. 5. Heat exchange between the greenhouse indoor air and soil for various soil types:

a) heat gains from soil, b) heat losses to soil

occurred in July $(90.92 \mathrm{kWh})$ with sandstone under the greenhouse (variant V). The lowest heat losses were recorded for variant II, also in July (49.48 kWh). The heat exchange between the greenhouse and the soil depends on the soil technical parameters. The studies have shown that the increase of thermal conductivity coefficient $(\lambda)$ by $1.9 \mathrm{~W} \cdot \mathrm{m}^{-1} \cdot \mathrm{K}^{-1}$ results in an increase of heat losses to soil by $84 \%$.

The results of the all-year-round analysis of heat exchange with soil have shown a significant contribution of soil to the heat losses for variant $\mathrm{V}$. The difference between the heat gains and losses was assumed and the results for individual months were compared. In comparison with the as-is state (variant I), the average monthly heat exchange with soil was twice as large. The extreme heat losses to soil in variant $\mathrm{V}$ were recorded in May, June and July (73.13-78.54 kWh). Significant heat losses to soil in the summer are advantageous in terms of maintaining the favourable thermal conditions in the growing zone. This contributes to removal of heat surplus from the greenhouse to the soil. The analysis results have shown that low soil thermal conductivity coefficient $\left(0.40 \mathrm{~W} \cdot \mathrm{m}^{-1} \cdot \mathrm{K}^{-1}\right)$ has an unfavourable 
a)

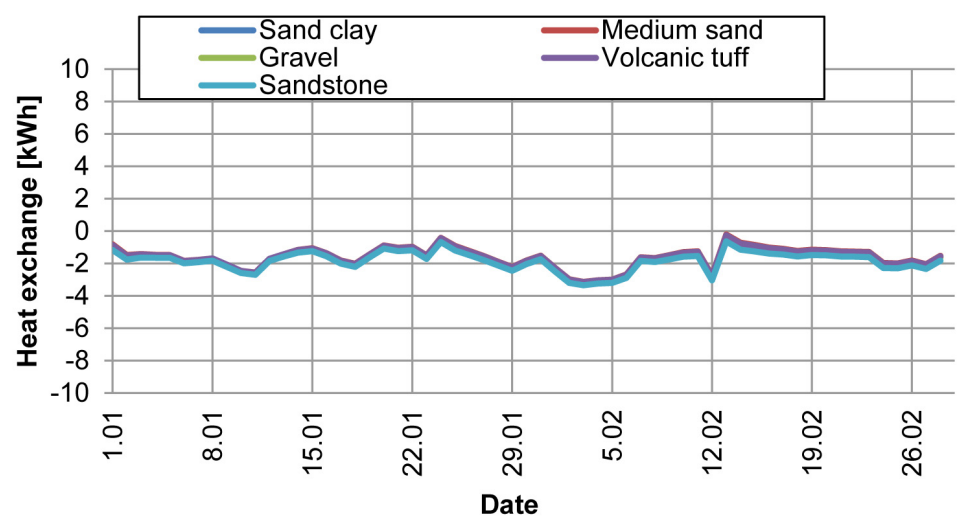

b)

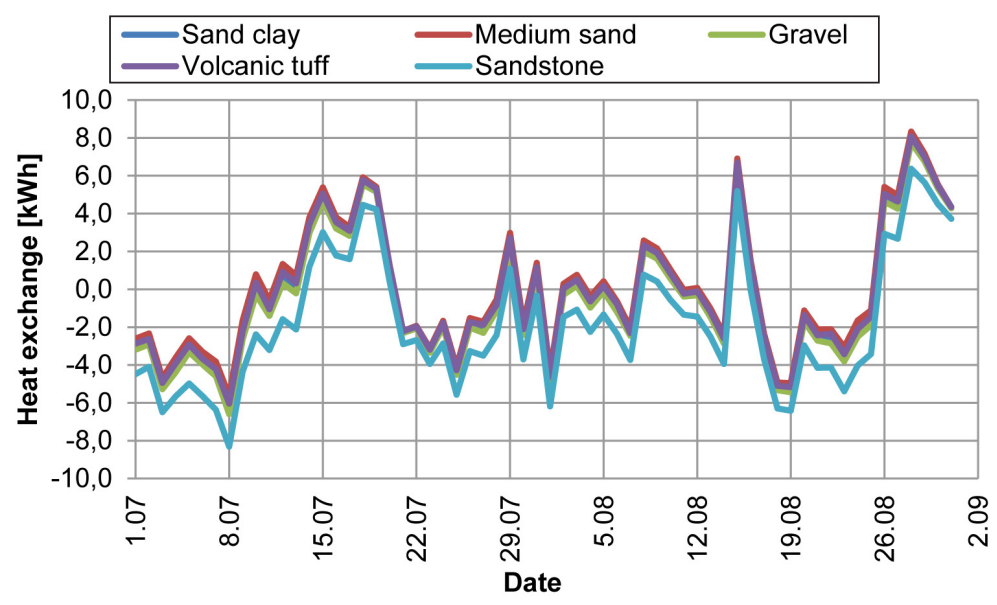

Fig. 6. Heat exchange between the greenhouse indoor air and various soils in periods:

a) winter (January-February), b) summer (July-August)

impact on the greenhouse energy management in the summer (variants II and IV). A greenhouse erected on medium sand (variant II) has the capability of heat removal to soil 5.5 less than a greenhouse erected on sandstone (variant V). In case of gravel under the greenhouse (variant III), the amount of heat removed to soil is $23 \%$ less than in case where sand clay is under the greenhouse (variant I).

The calculations have shown that high soil density $\left(2500 \mathrm{~kg} \cdot \mathrm{m}^{-3}\right)$ and high thermal conductivity coefficient $\left(2.30 \mathrm{~W} \cdot \mathrm{m}^{-1} \cdot \mathrm{K}^{-1}\right)$ have a favourable impact on the greenhouse energy management in the summer (Fig. 6). The dynamics of heat exchange with soil in that period is much higher than in transition periods and the winter. In winter, the heat exchange with soil is directed towards the heat losses to soil, which is unfavourable. The average monthly amplitude of heat exchange with soil in the winter period was $2.85 \mathrm{kWh}$, and $15.60 \mathrm{kWh}$ in the summer period.
Determination of the role of soil in the greenhouse energy management is not well researched in available papers. There are papers whose authors analyse, inter alia, the greenhouse material and design solutions, but limit their studies to the envelopes in contact with air. An example can be the paper by Fabrizio (2012) in which the author described the impact of materials of thermal insulation parameters superior to glass on the reduction of the greenhouse energy demand. The author made a simulation in the EnergyPlus software for a $40 \times 10 \mathrm{~m}$ greenhouse with glass envelopes replaced with polycarbonate panels. The analysis was based on the statistical climate in northern Italy, and the results showed that the use of polycarbonate panels instead of glass, while keeping required solar radiation transmission, can result in the reduction of heat losses through transparent envelopes by about $30 \%$.

The studies by the authors of this paper determine the role of soil in the greenhouse energy 
management. The appropriate temperature in soil will allow a further reduction of the greenhouse energy demand. The share of heat exchange with soil is only $5 \%$ of the total heat exchange through all envelopes (Nawalany et al., 2014). It should be emphasized that despite a seemingly small share in the greenhouse energy management, the soil plays an important part in the development of thermal conditions in the growing zone. The studies by Al-Kayssi (2002) showed a spatial variation of temperature in soil in the greenhouse at the depth of $0.05 \mathrm{~m}$. Such spatial variation is much greater $\left(18{ }^{\circ} \mathrm{C}\right)$ when the studies are conducted all year long. The temperature in soil under the greenhouse is influenced by the indoor and outdoor air temperatures. The soil has a favourable impact on limiting sudden temperature fluctuations in the growing zone. The simulation results have shown significant differences in heat exchange with soil depending on the soil technical parameters. Consequently, the greenhouse design should account for the soil type on which the greenhouse will be erected in terms of its heating energy demand.

\section{CONCLUSIONS}

The results of experimental studies allowed the determination of the soil temperature in the greenhouse surrounding. The knowledge of annual soil temperature curves allowed a detailed validation and calibration of the calculation model in the WUFIplus software. The validation results are considered reliable and allow the use of the model for simulation calculations of heat exchange with soil for various soil types used. The analysis of study results has proved that the soil type does affect the heat exchange between the greenhouse and the soil. Erecting a greenhouse on sandstone is most favourable from the energy point of view in the summer ( $90.92 \mathrm{kWh}$ of heat losses to soil). Low thermal conductivity coefficient, as in case of medium sand, adversely affects the removal of excess heat from the indoor air to the soil in the summer (49.48 kWh of heat losses to soil). Soils of low thermal conductivity coefficient, such as sand and volcanic tuff, can contribute to higher indoor temperatures in the plant growing zone. In case of gravel under the greenhouse, the amount of heat removed to soil is $23 \%$ less than in case where sand clay is under the greenhouse.

\section{REFERENCES}

1. Al-Kayssi A.W. 2002. Spatial variability of soil temperature under greenhouse conditions. Renewable Energy, 27, 453-462.

2. Bibbiani C., Fantozzi F., Gargari C., Campiotti C.A., Vox G. 2016. Wood biomass as sustainable energy for greenhouse heating in Italy. Agruculture and Agricultural Science Procedia, 8, 637-645.

3. Boughanmi H., Lazaar M., Guizani A. 2018. A performance of heat pump system connected a new conic heliocoidal geothermal heat exchanger for a greenhouse heating in the north of Tunisia. Solar Energy, 171, 343-353.

4. Canadas J., Sanchez-Molina J.A., Rodriguez F., Aguila I.M. 2017. Improving automatic climate control with decision support techniques to minimize disease effects in greenhouse tomatoes. Information Processing in Agriculture, 4, 50-63.

5. Deru M., Judkoff R., Neymark J. 2003. Whole Building Energy Simulation with a Three-Dimensional Ground-Coupled Heat Transfer Model. ASHRAE Transactions, 557-565.

6. Esen M., Yuksel T. 2013. Experimental evaluation of using various renewable energy sources for heating a greenhouse. Energy and Buildings, $65,340-351$.

7. Fabrizio E. 2012. Energy reduction measures in agricultural greenhouses heating: Envelope, systems and solar energy collection. Energy and Buildings, 53, 57-63.

8. Fox J.A., Adriaanse P., Stacey N.T. 2019. greenhouse energy management: The thermal interaction of greenhouses with the ground. Journal of Cleaner Production, 235, 288-296.

9. Hassanien R.H.E., Li M., Dong Lin W. 2016 Advanced applications of solar energy in agricultural greenhouses. Renewable Sustainable Energy, 54, 989-1001.

10. Hassanien R.H.E., Li M., Tang Y. 2018. The evacuated tube solar collector assisted heat pump for heating greenhouses. Energy and Buildings, 169, 305-318.

11. Kittas C., Karamanis M., Katsoulas N. 2005. Air temperature regime in a forced ventilated greenhouse with rose crop. Energy and Buildings, 37, 807-812.

12. Kurpaska S. 2008. Wymiary geometryczne oraz rodzaj pokrycia a zapotrzebowanie ciepła w szklarni. Inżynieria Rolnicza, 6, 89-96.

13. Kurpaska S., Latała H., Rutkowski K., Hołownicki R., Konopacki P., Nowak J., Treder W. 2012. Magazynowanie nadwyżki ciepła $\mathrm{z}$ tunelu foliowego $\mathrm{w}$ akumulatorze ze złożem kamiennym. Inżynieria Rolnicza, 2, 157-167. 
14. Liang M.H., He Y.F., Chen L.J., Du S.F. 2018. Greenhouse environment dynamic monitoring system based on WIFI. IFAC-PapersOnLine, 51, 736-740.

15. Nawalany G., Bieda W., Radoń J., Herbut, P. 2014. Experimental study on development of thermal conditions in ground beneath a greenhouse. Energy Building, 69, 103-111.

16. Nawalany G., Sokołowski P. 2016. Analysis of hygrothermal conditions of external partitions in an underground fruit store. Journal of Ecological Engineering, 17(4), 75-82.

17. Nawalany G., Sokołowski P. 2019. Building-Soil Thermal Interaction: A Case Study. Energies, 12, Iss. 15, Article number 2922.

18. Nawalany G., Sokołowski P., Herbut P., Angrecka S. 2017b. Development of selected parameters of microclimate in a stand alone cellar plunged into soil. Journal of Ecological Engineering, 18(3), 156-161.

19. Nawalany G., Radon J., Bieda W., Sokolowski P. 2017a. Influence of selected factors on heat exchange with the ground in a greenhouse. Transactions of the ASABE, 60(2), 479-487.

20. Papadopoulos A.P., Hao X. 1997. Effects of greenhouse covers on seedless cucumber growth, productivity and energy use. Science Horticulturae, 68, 113-123.

21. Raczek A., Wachowicz E. 2014. Model procesu wymiany ciepła i masy w powietrzu wewnatrz szklarni. Inżynieria Rolnicza, 1, 185-195.

22. Sagrado J., Sanchez J.A., Rodriguez F., Berenguel M. 2016. Byesian networks for greenhouse temperature control. Journal of Applied Logic, 17, 25-35.

23. Sethi V.P., Sharma S.K. 2007. Survey of cooling technologies for worldwide agricultural greenhouse applications. Solar Energy, 81, 1447-1459.

24. Taki M., RohaniA., Rahmati-Joneidabad M. 2018. Solar thermal simulation and applications in greenhouse. Information Processing in Agriculture, 5, 83-113.

25. Tong G., Christopher D.M., Li B. 2009. Numerical modelling of temperature variations in a Chinese solar greenhouse. Computers and Electronics in Agriculture, 68, 129-139.

26. Vadiee A., Martin V. 2013. Thermal energy storage strategies for effective closed greenhouse design. Applied Energy, 109, 337-343.

27. Wang J., Zhou J., Gu R., Chen M., Li P. 2018. Manage system for internet of things of greenhouse based on GWT. Information Processing in Agriculture, 5, 269-278. 